\title{
Physical Activity Index among Malaysian Youth
}

\author{
Norlena Salamudin ${ }^{1} \&$ Mohd Taib Harun ${ }^{1}$ \\ ${ }^{1}$ Faculty of Education, Universiti Kebangsaan Malaysia, Selangor, Malaysia \\ Correspondence: Norlena Salamudin, Faculty of Education, Universiti Kebangsaan Malaysia, 43600 UKM \\ Bangi, Selangor, Malaysia. E-mail: lena@ukm.my
}

Received: August 1, 2013 Accepted: August 16, 2013 Online Published: August 30, 2013

doi:10.5539/ass.v9n12p99 URL: http://dx.doi.org/10.5539/ass.v9n12p99

\begin{abstract}
Over the last several years, physical inactivity has increasingly been recognized as a major health risk among Malaysians. The Government of Malaysia under the Ministry of Youth has adopted many programs aiming at keeping the nation healthy. Among such programs are Malaysia Cergas and RakanSukan. Trends in the physical activity levels and participation patterns of Malaysians has never been researched or monitored. Thus, there is no available evidence to serve as a foundation for decision making regarding this matter. This research was conducted with the aim of providing a unique insight into the physical activity patterns and fitness levels of Malaysian youths, as well as providing a detailed baseline data that can be use for developing policy and planning physical activity strategies for the youths. This article provides insights into the current physical activity levels among Malaysian youths in the Klang Valley and the prognosis for change; the individual and collective benefits of a more active Malaysia; and, the type of strategies needed to help Malaysians especially the youths, become and remain active.
\end{abstract}

Keywords: physical activity, youth, Malaysia

\section{Introduction}

This article provides a picture of the current situation in Malaysia that is relevant to policy and decision-makers in designing initiatives to decrease sedentary living especially among the youth. The study is deemed important as, off late, there is an increase in the number of deaths related to sedentary lifestyle especially among the youths in Malaysia. The study conducted provides information on participation in physical activity, describes specific benefits to be gained from reducing physical inactivity, highlights public support for government investment in various initiatives and outlines the types of strategies that are most promising for helping Malaysian youths to become and remain active. However, this article focuses on the physical activity profile of Malaysian youths according to age, gender and race. This article concludes with suggestions in making a difference by giving some considerations for developing initiatives related to education, supports, and changing the social and physical environments.

The twenty first century has witnessed profound changes in health promotion in Malaysia. Professions related to health, especially the medical profession took the lead and assured the public that the medical system could provide the best medical care. The system that emerged to provide for the individual was based on the assumption that health depended on the control of disease. The popular notion is that disease could best be controlled by individuals who had the understanding of the anatomy, physiology and pathology of the human body, whom can apply this knowledge in medical intervention. That knowledgeable authority figure, the medical doctor, was assumed to be responsible for the health of his or her patients. The patient, impressed by countless miraculous medical breakthroughs, was made to feel inadequate in matters of health. In addition, the media also assured the public that they could eat, drink, and be merry without any thoughts of tomorrow. The world's best medical resources were at their disposal, when and if they needed it. As a result, society grew indifferent about personal behaviour as a principal determinant of health. Individual's responsibility for health was forgotten. Health was considered the absence of disease, and society had been convinced that disease could be controlled. Furthermore, society was informed that technology could provide the solution to any problem. Therefore the medical system was given the priority. It was believed that if enough money was invested in the system, the answers would come pouring out. For some time, this outcome was achieved. Faced with problems of infectious diseases, the weapon was the antibiotics. As soon as a bacterium developed resistance to one antibiotic, new drugs were introduced with a broader spectrum of effectiveness. By the mid twentieth century, the acute 
infectious diseases were under control. Preparations to combat the next wave of diseases then begin. Now the diseases are more chronic and had become the new killers. These diseases are the heart disease, cancer and stroke. It was believed that superior technology can manage to handle these diseases. However, they are proving to be more stubborn than was expected. The problem is that there are no miracle cures for these diseases. They are the result of the life-style of the individual (U.S. Department of Health, 1979). They are determined by nutrition, physical fitness, handling of stress, choice of environment and use of alcohol, tobacco and drugs. In short, they are determined by behavior and can be controlled only by its modification (Kelogg Foundation, 1990) It is hypothesized that increasing physical activity is cost effective in reducing discounted lifetime costs of health care and disability insurance, reducing annual direct health care costs, reducing absenteeism to increase productivity and maintaining independence of older adults. A longitudinal study among Canadian youth reported that only two fifth of Canadian children and youth are active, thus indicating that they are at a greater risk of contracting diseases which is due to sedentary life (Boyuk, 2002). Another study by Canadian Fitness and Lifestyle Research Institute (2004) reported that social, physical and environmental wellbeing plays a role in youth adherence towards active lifestyle which translates into a better quality of life. To date there has been little information available on the physical activity patterns of children and youth. This study will provide information on, among other things, physical activity, wellbeing and many associated factors. This study will focus on factors such as social and physical wellbeing which will describe the behaviour, academic achievement and health of Malaysian children and youth and also social and physical environment which will describe environmental and individual factors.

\section{Methodology}

A physical activity index survey is a questionnaire administered to a random sample of Malaysian youths residing in the Klang Valley. Findings of this study were based on a sample of 1801 Malaysian youth residing in the Klang Valley. Although the sample is too small for a detailed analysis, overall estimates are provided as appropriate for the Klang Valley. Data were collected via assistant researchers with a randomly selected individuals aged 18 through 25 years of age. Further details about the sampling and data collection procedures are given below.

The Malaysia Physical Activity Index Survey was conducted over a period of 6 months. The long duration in data collection were made in order to get a more meaningful result of the survey. Topics included in the questionnaire were decided upon consultation with other researchers in the team after several meetings. The survey is designed to meet two objectives:

1) to provide data on physical activity levels and patterns, including energy expenditure, and participation rates in various types of activities for Malaysians aged 18 through 25; and,

2) to provide information on factors influencing participation in physical activity, including barriers and readiness to be active, the importance of physical activity to an individual's well-being and important supports for an active lifestyle.

Data were captured directly on the questionnaire. All numbers have a statistical error associated with them by virtue of the random selection of the sample.

\section{Results}

Results of the study focuses on the physical activity index of Malaysian youths and are explained according to age, gender and race using both descriptive and inferential statistics. 
Table 1. Descriptive analysis of sample

\begin{tabular}{|c|c|c|c|}
\hline & & $\mathrm{n}$ & $\%$ \\
\hline \multirow[t]{2}{*}{ Gender } & Male & 829 & $46 \%$ \\
\hline & Female & 972 & $54 \%$ \\
\hline \multirow[t]{8}{*}{ Age } & 18 & 237 & $13.2 \%$ \\
\hline & 19 & 214 & $11.9 \%$ \\
\hline & 20 & 220 & $12.2 \%$ \\
\hline & 21 & 256 & $14.2 \%$ \\
\hline & 22 & 218 & $12.1 \%$ \\
\hline & 23 & 216 & $12.0 \%$ \\
\hline & 24 & 223 & $12.4 \%$ \\
\hline & 25 & 217 & $12.0 \%$ \\
\hline \multirow[t]{4}{*}{ Race } & Malay & 884 & $49.1 \%$ \\
\hline & Chinese & 513 & $28.5 \%$ \\
\hline & Indian & 347 & $19.3 \%$ \\
\hline & Others & 57 & $3.2 \%$ \\
\hline
\end{tabular}

Table 1 shows the description of the sample. Age, race and gender are included in the analysis because the researchers believe that these three factors play an important role in participation in physical activity. Malaysia is steep in cultural believes, thus race of the individual may influence their participation in physical activity.

Table 2. Overall physical activity index

\begin{tabular}{ccccc}
\hline & Index & n & \multicolumn{2}{c}{$\%$} \\
\hline \multirow{2}{*}{ Overall } & Low & 495 & $27.5 \%$ \\
& & Intermediate & 1306 & $72.5 \%$ \\
\hline
\end{tabular}

The overall physical activity index of Malaysian youths sampled in this study is shown in Table 2. Majority of the sample is in the intermediate category and none is in the high category. Intermediate category suggests that Malaysia youth in leading o sedentary to moderately active lifestyle.

Table 3. Physical activity index according to gender

\begin{tabular}{|c|c|c|c|c|c|c|c|}
\hline & & Index & $\mathbf{n}$ & $\%$ & m (sd) & Levene's & $\mathbf{t}$ \\
\hline \multirow[t]{4}{*}{ Gender } & Male & Low & 191 & $23 \%$ & $1.77(0.42)$ & \multirow{4}{*}{$63.27^{*}$} & \multirow{4}{*}{$3.92 *$} \\
\hline & \multirow{3}{*}{ Female } & Intermediate & 638 & $77 \%$ & \multirow{3}{*}{$1.69(0.49)$} & & \\
\hline & & Low & 304 & $31.3 \%$ & & & \\
\hline & & Intermediate & 668 & $68.7 \%$ & & & \\
\hline
\end{tabular}

Referring to Table 3, the index between male and female do not differ much but percentages shows that male is slightly active than their female counterpart. However, further test shows that there is a significant difference between male and female in physical activity participation $(\mathrm{t}=3.92, \mathrm{p}<0.05)$. 
Table 4. Physical activity index according to race

\begin{tabular}{|c|c|c|c|c|c|c|c|}
\hline & & Index & $\mathbf{n}$ & $\%$ & m (sd) & $\mathbf{F}$ & df \\
\hline \multirow[t]{8}{*}{ Race } & Malay & Low & 244 & $27.6 \%$ & $1.72(0.45)$ & \multirow{8}{*}{0.70} & \multirow{8}{*}{$\begin{array}{r}3 \\
179\end{array}$} \\
\hline & & Intermediate & 640 & $72.4 \%$ & & & \\
\hline & Chinese & Low & 145 & $28.3 \%$ & $1.72(0.45)$ & & \\
\hline & & Intermediate & 368 & $71.7 \%$ & \multirow{3}{*}{$1.73(0.45)$} & & \\
\hline & Indian & Low & 95 & $27.4 \%$ & & & \\
\hline & \multirow{3}{*}{ Others } & Intermediate & 252 & $72.6 \%$ & & & \\
\hline & & Low & 11 & $19.3 \%$ & \multirow[t]{2}{*}{$1.81(0.40)$} & & \\
\hline & & Intermediate & 46 & $80.7 \%$ & & & \\
\hline
\end{tabular}

Analysis according to race shows no significant differences in physical activity index among the four main races in Malaysia.

Table 5. Physical activity index according to age

\begin{tabular}{|c|c|c|c|c|c|c|c|}
\hline & & Index & $\mathbf{n}$ & $\%$ & m (sd) & $\mathbf{F}$ & df \\
\hline \multirow[t]{16}{*}{ Age } & 18 & Low & 51 & $21.5 \%$ & $1.78(0.41)$ & \multirow{16}{*}{$25.15^{*}$} & \multirow{16}{*}{$\begin{array}{c}7 \\
1793\end{array}$} \\
\hline & & Intermediate & 186 & $78.5 \%$ & & & \\
\hline & \multirow[t]{2}{*}{19} & Low & 71 & $33.2 \%$ & $1.67(0.47)$ & & \\
\hline & & Intermediate & 143 & $66.8 \%$ & & & \\
\hline & \multirow[t]{2}{*}{20} & Low & 7 & $3.2 \%$ & $1.97(0.17)$ & & \\
\hline & & Intermediate & 213 & $96.8 \%$ & & & \\
\hline & \multirow[t]{2}{*}{21} & Low & 134 & $52.3 \%$ & $1.48(0.50)$ & & \\
\hline & & Intermediate & 122 & $47.7 \%$ & & & \\
\hline & \multirow[t]{2}{*}{22} & Low & 46 & $21.1 \%$ & $1.79(0.41)$ & & \\
\hline & & Intermediate & 172 & $78.9 \%$ & & & \\
\hline & \multirow[t]{2}{*}{23} & Low & 72 & $33.3 \%$ & $1.67(0.47)$ & & \\
\hline & & Intermediate & 144 & $66.7 \%$ & & & \\
\hline & \multirow[t]{2}{*}{24} & Low & 58 & $26 \%$ & $1.74(0.44)$ & & \\
\hline & & Intermediate & 165 & $74 \%$ & & & \\
\hline & \multirow[t]{2}{*}{25} & Low & 56 & $25.8 \%$ & $1.74(0.44)$ & & \\
\hline & & Intermediate & 161 & $74.2 \%$ & & & \\
\hline
\end{tabular}

Analysis according to gender showed that there is a significant difference in physical activity index between the ages $(\mathrm{F}=25.15, \mathrm{p}<0.05)$. Therefore post-hoc test was conducted to see which age group is more active than the others. Table 6 shows the results of the post-hoc test. 
Table 6. Results of post-hoc test for physical activity index according to age

\begin{tabular}{ccccccccc}
\hline Age & $\mathbf{1 8}$ & $\mathbf{1 9}$ & $\mathbf{2 0}$ & $\mathbf{2 1}$ & $\mathbf{2 2}$ & $\mathbf{2 3}$ & $\mathbf{2 4}$ & $\mathbf{2 5}$ \\
\hline $\mathbf{1 8}$ & - & NS & $-0.18^{*}$ & $0.31^{*}$ & NS & NS & NS & NS \\
$\mathbf{1 9}$ & & - & $-0.30^{*}$ & $0.19^{*}$ & NS & NS & NS & NS \\
$\mathbf{2 0}$ & & & - & $0.49^{*}$ & $0.18^{*}$ & $0.30^{*}$ & $0.23^{*}$ & $0.23^{*}$ \\
$\mathbf{2 1}$ & & & & - & $-0.31^{*}$ & $-0.19^{*}$ & $-0.26^{*}$ & $-0.27^{*}$ \\
$\mathbf{2 2}$ & & & & & - & NS & NS & NS \\
$\mathbf{2 3}$ & & & & & & - & NS & NS \\
$\mathbf{2 4}$ & & & & & & & - & NS \\
$\mathbf{2 5}$ & & & & & & & & - \\
\hline
\end{tabular}

Result of the post hoc test shows that Malaysian youth at the age of 21 is more active than the rest of the ages. However at the age of 22 and above, the sample studied showed that these youth reduces their physical activities. This may be due to work and studies constraint which make them spend less time on being active and more time sitting.

\section{Discussion}

It has been noted worldwide that once a student's leave schools they become laid back. Their physical activity level decreases. However no studies have been conducted on the profile of physical activity levels among Malaysians of all ages. Therefore, this researcher could not determine the trends and benchmark the physical activity levels of Malaysian youths.

Age and sex related differences in activity levels do exist. Women tend to be less active overall than men, with $31.3 \%$ counted as sedentary compared with $23 \%$ of men.

The time spent in physical activities on the average is 10 hours per week. On the average women spend 8 hours per week doing physical activities while men spend on the average 12 hours per week. Popular activities among youths include skate boarding, bicycling, walking, basketball and running or jogging.

The situation for youth overall is good as they are spending an average of 1.5 hours per day on physical activities. But when it is break down to gender, women are spending about 1.14 hours a day on physical activities. The sex related differences noted in the types of activities in which youths engage may be related to developmental differences in motor abilities as well as environmental factors like access to opportunities.

While participation in vigorous intensity activities such as jogging is prevalent, moderate and light intensity activities such as bicycling, home exercise, walking and gardening are also rated highly among the youths. However, activity choices differ, both quantitatively and qualitatively, between ages, and, between men and women. With the exception of walking, the participation rates in activities decreases with age. Team sports and vigorous intensity activities tend to be choices of younger age groups, particularly younger men. More women than men participate in activities such as walking, home exercise, exercise classes and aerobics, whereas men more frequently cite participation in activities such as bicycling, jogging, weight training, golf, tennis and team sports.

\section{Conclusion}

Over the next years, the level of physical inactivity must show a declining rate. Malaysia should set a target of reducing physical inactivity among its youth by $10 \%$ by the year 2016 . The rate of decline must be great if this target is to be met. If there are only small declines in the level of physical inactivity, it may be troubling given that physical inactivity is pervasive in the Malaysian culture. If the decline progress stalls, it reinforces the need for a more concerted effort to address the issue of inactivity, not just by making active pursuits more appealing to individuals, but more importantly by making the social and physical environments in which the youth work, study, live and play more conducive to physical activity. Being active must be feasible and a relatively easy option. Fortunately, the Government has begun to enact change strategies since the establishment of various health and fitness related programs. As with any change strategy, the impact should be expected to begin slowly and increase gradually over the next few years until a momentum builds.

Many Malaysian youths build physical activity into their daily lives through choices they make at work, at college and at other times. Taking the stairs whenever possible is the most frequent way to incorporate physical 
activity into daily life, followed by choosing to do chores for exercise and walking part way to work or class. Bicycling to work or college or to do errands is a much less frequent choice.

Incorporating physical activity into the daily routine increases with age. Older youths choose to take the stairs or do heavy housework compared with younger age youths. Men are more likely than women to choose taking the stairs over elevators and walking part way to work, college or when doing errands. Whereas men are more likely to report doing heavy chores for exercise, women are more likely to report choosing light chores.

The popular activity choices are ones that integrate well into daily life. Many are unstructured, relatively low cost activities that can be done outside with a minimum of equipment. Supporting and encouraging Malaysian youths to participate more often in their current activities is perhaps the key in progressing toward a more active Malaysia.

It should be concluded that the state of physical activity among Malaysian youths is still low to intermediate. With the accelerating rate of death due to a sedentary lifestyle which is slowly creeping among the youth, this is a good opportunity for each and every individual to look back and review their current lifestyle and incorporate physical activity into it.

\section{References}

Brown, W. J., Burton, N. W., \& Rowan, P. J. (2007). Updating the evidence on physical activity and health in women. Am J Prev Med., 33(5), 404-411. http://dx.doi.org/10.1016/j.amepre.2007.07.029

Craig, C. I., Marshall, A. L., Sjostrom, M., Bauman, A., Booth, M. L., \& Ainsworth, B. E. (2003). International Physical Activity Questionnaire: 12 country reliability and validity. Medicine and science in sports and exercise, 35, 1381-1395. http://dx.doi.org/10.1249/01.MSS.0000078924.61453.FB

Kohl, H. W., Lee, I. M., Vuori, I. M., Wheeler, F. C., Bauman, A., \& Sallis, J. F. (2006). Physical Activity and Public Health: The Emergence of a Subdiscipline. Journal of Physical Activity and Health, 3, 344-364.

Kohl, H. W., Lee, I. M., Vuori, I. M., Wheeler, F. C., Bauman, A., \& Sallis, J. F. (2011). Exercise intensity. Working out in the right range. Mayo Clinic Women's Healthsource, 15(3), 7.

Kohl, H. W., Lee, I. M., Vuori, I. M., Wheeler, F. C., Bauman, A., \& Sallis, J. F. (2010). Looking for a panacea? Just keep moving. Harvard Health Letter, 35(8), 7.

Neithercott, T. (2009a). Defining a moderate-intensity workout. A simple walking test can gauge the intensity of your walking pace. Harvard Heart Letter, 19(10), 1.

Neithercott, T. (2009b). Exercise: good questions (and answers). Diabetes Forecast, 62(7), 44-50.

Neithercott, T. (2010). Break your routine: Fun fitness ideas for everybody. Diabetes Forecast, 63(7), 42-46.

World Health Organization. (2004). Global Strategy on Diet, Physical Activity and Health.

\section{Copyrights}

Copyright for this article is retained by the author(s), with first publication rights granted to the journal.

This is an open-access article distributed under the terms and conditions of the Creative Commons Attribution license (http://creativecommons.org/licenses/by/3.0/). 